\title{
A Method for Quantifying Whole-tree Pruning Severity in Mature Tall Spindle Apple Plantings
}

\author{
James R. Schupp ${ }^{1}$, H. Edwin Winzeler, Thomas M. Kon, \\ Richard P. Marini, Tara A. Baugher, Lynn F. Kime, \\ and Melanie A. Schupp \\ Department of Plant Sciences, Pennsylvania State University, Fruit Research \\ and Extension Center, 290 University Drive, Biglerville, PA 17307-9585
}

Additional index words. Malus $\times$ domestica (Borkh.), renewal growth, yield, yield efficiency, crop load, fruit quality

\begin{abstract}
Pruning is the cutting away of vegetation from plants for horticultural purposes. Pruning is known to reduce apple tree size, increase fruit size and quality, and decrease yield. Methods for studying the effects of varying degrees of severity of pruning on a whole-tree basis have used qualitative descriptions of treatments rather than repeatable whole-tree quantitative metrics. In this study, we introduce a pruning severity index calculated from the sum of the cross-sectional area of all branches on a tree at $2.5 \mathrm{~cm}$ from their union to the central leader divided by the cross-sectional area of its central leader at $30 \mathrm{~cm}$ from the graft union. This limb to trunk ratio (LTR) was then modified by successively removing the largest branches of 'Buckeye Gala' to achieve six severity levels ranging from LTR 0.5 to LTR 1.75, with lower values representing more extreme pruning with less whole-tree limb area relative to trunk area. Pruning treatments were applied for three consecutive years and tree growth and cropping responses were observed for the first 2 years. With increasing pruning severity the following characteristics increased after seasonal growth: number of renewal limbs, number of shoots, shoot length, number of shoot leaves, shoot leaf area, final fruit set, fruit size, yield of large fruit, crop value from large fruit, soluble solids, and titratable acidity. The following characteristics decreased: limb age, number of secondary limbs, number of spurs, number of spur leaves, spur leaf area, the ratio of spur leaf area to shoot leaf area, fruit count per tree, yield, yield efficiency, crop value from small fruit, overall crop value, and sugar:acid ratio. The LTR provides a measurable way to define and create different levels of pruning severity and achieve consistent outcomes. This allows a greater degree of accuracy and precision to dormant pruning of tall spindle apple trees. The use of the LTR to establish the level of pruning severity allows the orchard manager to set crop load potential through regulation of the canopy bearing surface. This metric is also a necessary step in the development of autonomous pruning systems.
\end{abstract}

Pruning is the cutting away of vegetation from plants for horticultural purposes. In apple production, trees are pruned to open the canopy to sunlight, facilitate fruit bud formation, promote fruit ripening and color development, facilitate the movement of air and sprays of protective chemicals, keep tree size within desirable limits, and manipulate the natural balance between vegetative and reproductive structures (Ferree and Schupp, 2003; Fumey et al., 2011; Jonkers, 1982). Pruning has long been recognized as a dwarfing practice, resulting in trees that are smaller than unpruned trees, with effects on vegetative growth, flowering propensity, fruit quality,

\footnotetext{
Received for publication 12 June 2017. Accepted for publication 13 July 2017.

The authors gratefully acknowledge funding support from the USDA NIFA Specialty Crop Research Initiative (Grant no. 2012-51181-19878) and the State Horticultural Association of Pennsylvania, along with industry partners who provided project matching funds.

${ }^{1}$ Corresponding author. E-mail: jrs42@psu.edu.
}

fractions of their original length (Jonkers, 1982). Gardner describes whole-tree studies in which pruning severity was classed with qualitative rather than quantitative terms, such as heavy, moderate, and light pruning (Gardner et al., 1922). Howe (1923) compared growth and fruiting of young apple trees over a 10-year period. Trees were pruned from years 2 to 4 with either light corrective pruning or corrective pruning plus heading of one half to two thirds of the scaffolds. Lightly pruned apple trees developed a larger canopy, and were more precocious, but pruning effects on yield were not consistent across varieties. Some studies compared pruned with nonpruned trees without varying the levels of severity or severe shoot heading in dormant pruned vs. summer pruned trees (Marini and Barden, 1982a, 1982b; Fumey et al., 2011). Elfving and Forshey (1976) reported that heading successively longer sections of 1 -year-old wood from vigorous 8-year-old 'Delicious'/ 'M.7' apple trees increased shoot growth and decreased subsequent fruiting because of reduced bearing surface. Although the benefits of pruning on growth, yield, fruit size, and fruit quality have long been known, the large, complex tree architecture of apple trees on vigorous rootstocks, coupled with fruits being born on spurs originating on 2-year-old wood and older created difficulties with establishment of simple repeatable pruning severity thresholds for whole trees.

Apple trees on dwarfing rootstocks planted at high density have become the industry standard and have gained wide acceptance (Robinson, 2003). In high-density "spindle" systems, every primary limb (a limb that originates from the main trunk or "spindle") is expected to be removed at some point, with large limbs preferentially removed, and the central leader left as the only permanent part of the canopy. The productivity and simplicity of the tall spindle system has led to wide acceptance (Robinson et al., 2006), in part, because it leads to ease of automation and simplification of management. In this system, removal of the largest limbs is most important. Large limbs tend to be more vigorous and vegetative, and less fruitful than smaller limbs. Removing large limbs stimulates smaller, more fruitful, and renewal limbs that better fit the tall spindle orchard system.

In the renewal pruning of a spindle system during dormancy, excess side branches are removed preferentially by size, leaving a short beveled stub at the base to stimulate renewal growth (Wertheim, 1968). Renewal branches develop and replace the current side branches when these have grown too large and are removed by pruning. Renewal pruning is key to maintaining fruit quality through renewing spurs and creating a favorable light environment. The optimum number of fruiting laterals that should remain after pruning to optimize crop production was described for peach (Marini, 2003) but is not well defined for apple. Unlike peach, apple bears fruit from mixed buds on different ages of 
Table 1. Various response variables as affected by pruning treatment over 3 years. Significant regression model terms are listed below the means for each response variable. $^{\mathrm{z}}$

\begin{tabular}{|c|c|c|c|c|c|c|c|c|c|c|}
\hline $\begin{array}{l}\text { Pruning severity } \\
\text { level (LTR) }\end{array}$ & $\mathrm{Yr}$ & $\begin{array}{c}\operatorname{TCSA}^{\mathrm{y}} \\
\text { spring }\left(\mathrm{cm}^{2}\right)\end{array}$ & $\begin{array}{c}\text { Total } \\
\text { limbs spring } \\
\text { (no. per tree) }\end{array}$ & $\begin{array}{c}\text { Number of } \\
\text { limbs removed } \\
\text { in spring } \\
\text { (no. per tree) }\end{array}$ & $\begin{array}{l}\mathrm{LCSA}^{\mathrm{x}} \text { before } \\
\text { pruning }\left(\mathrm{cm}^{2}\right)\end{array}$ & $\begin{array}{c}\text { LCSA } \\
\text { removed }\left(\mathrm{cm}^{2}\right)\end{array}$ & $\begin{array}{l}\text { Limb wt } \\
\text { removed }(\mathrm{kg})\end{array}$ & $\begin{array}{l}\text { Mean limb } \\
\text { CSA }\left(\mathrm{cm}^{2}\right)\end{array}$ & $\begin{array}{l}\text { Number of } \\
\text { renew limbs } \\
\text { (no.) }\end{array}$ & $\begin{array}{c}\mathrm{L}: \mathrm{T} \text { increase } \\
\left(\mathrm{cm}^{2} \cdot \mathrm{cm}^{-2}\right)\end{array}$ \\
\hline 1.75 & 1 & 26.7 & 73.3 & 1.0 & 51.3 & 4.1 & 0.3 & 3.9 & 0.7 & 0.3 \\
\hline 1.50 & & 34.4 & 77.8 & 2.0 & 57.1 & 6.1 & 0.8 & 3.0 & 4.0 & 0.6 \\
\hline 1.25 & & 35.0 & 77.5 & 5.2 & 60.5 & 16.7 & 1.7 & 3.5 & 6.7 & 0.5 \\
\hline 1.00 & & 34.4 & 86.0 & 9.5 & 55.5 & 20.8 & 2.1 & 2.6 & 6.3 & 0.5 \\
\hline 0.75 & & 25.5 & 74.7 & 19.7 & 48.0 & 28.9 & 2.5 & 1.5 & 16.3 & 0.9 \\
\hline 0.50 & & 30.2 & 78.0 & 27.5 & 53.5 & 34.6 & 3.5 & 1.4 & 29.0 & 1.1 \\
\hline 1.75 & 2 & 28.7 & 66.8 & 2.3 & 59.4 & 11.3 & 1.1 & 4.6 & 5.7 & 0.4 \\
\hline 1.50 & & 38.2 & 77.8 & 5.2 & 77.8 & 22.3 & 1.8 & 4.3 & 9.3 & 0.5 \\
\hline 1.25 & & 40.1 & 78.5 & 7.5 & 71.3 & 22.6 & 1.8 & 3.1 & 7.0 & 0.6 \\
\hline 1.00 & & 39.6 & 80.3 & 8.7 & 60.4 & 21.7 & 2.3 & 2.5 & 12.3 & 0.9 \\
\hline 0.75 & & 28.3 & 70.8 & 17.0 & 45.1 & 24.4 & 1.9 & 1.5 & 27.0 & 1.0 \\
\hline 0.50 & & 34.9 & 79.3 & 28.3 & 53.3 & 36.2 & 2.4 & 1.3 & 34.3 & 1.0 \\
\hline 1.75 & 3 & 32.9 & 71.7 & 3.0 & 72.8 & 14.2 & 1.5 & 5.4 & - & - \\
\hline 1.50 & & 43.0 & 81.0 & 4.7 & 86.1 & 20.3 & 2.3 & 4.7 & - & - \\
\hline 1.25 & & 46.0 & 77.0 & 9.0 & 78.7 & 25.1 & 2.7 & 2.9 & - & - \\
\hline 1.00 & & 45.8 & 84.3 & 9.0 & 88.0 & 28.2 & 2.7 & 3.2 & - & - \\
\hline 0.75 & & 32.6 & 79.3 & 25.3 & 52.5 & 30.0 & 2.2 & 1.2 & - & - \\
\hline 0.50 & & 39.8 & 85.7 & 30.3 & 58.5 & 39.7 & 2.8 & 1.3 & - & - \\
\hline \multicolumn{11}{|c|}{$P$ values for variables in regression model } \\
\hline Year & & 0.014 & - & 0.184 & 0.006 & 0.021 & 0.064 & - & 0.005 & - \\
\hline Trt & & 0.019 & - & 0.001 & 0.034 & 0.001 & 0.001 & 0.001 & 0.001 & 0.001 \\
\hline $\mathrm{Trt}^{2}$ & & 0.018 & - & 0.001 & 一 & 一 & - & - & 0.001 & - \\
\hline Year $\times$ Trt & & - & 一 & - & - & - & 0.014 & - & - & - \\
\hline
\end{tabular}

$\mathrm{z}$ - indicates that the term was not significant at the 5\% level and was deleted during the model selection process.

${ }^{\mathrm{y}}$ TCSA is the cross-sectional area of the central leader (or trunk) at $30 \mathrm{~cm}$ above the graft union.

${ }^{\mathrm{x}} \mathrm{LCSA}$ is the sum of the cross-sectional area of all the limbs on the tree at $2.54 \mathrm{~cm}$ from their union with the central leader.

Table 2. Regression models for variables shown in Table 1 obtained from the solution matrix with Proc Mixed.

\begin{tabular}{lll}
\hline Variable & Yr & \multicolumn{1}{c}{ Regression model } \\
\hline TCSA & 1 & $10.22+42.86(\operatorname{trt})-18.94\left(\operatorname{trt}^{2}\right)$ \\
& 2 & $14.15+42.86(\operatorname{trt})-18.94\left(\operatorname{trt}^{2}\right)$ \\
Limbs removed & 3 & $19.24+42.86(\operatorname{trt})-18.94\left(\operatorname{trt}^{2}\right)$ \\
& 1 & $54.54-62.58(\operatorname{trt})-18.41\left(\operatorname{trt}^{2}\right)$ \\
Total LCSA & 2 & $55.24-62.58(\operatorname{trt})-18.41\left(\operatorname{trt}^{2}\right)$ \\
& 3 & $57.30-62.58(\operatorname{trt})-18.41\left(\operatorname{trt}^{2}\right)$ \\
LCSA removed & 1 & $40.48+12.30(\operatorname{trt})$ \\
& 2 & $47.39+12.30(\operatorname{trt})$ \\
Wt removed & 3 & $58.93+12.30(\operatorname{trt})$ \\
& 1 & $44.49-23.15(\operatorname{trt})$ \\
Renewal & 2 & $49.10-23.15(\operatorname{trt})$ \\
L:T increase & 3 & $52.29-23.15(\operatorname{trt})$ \\
& 1 & $4.61-2.47(\operatorname{trt})$ \\
\hline
\end{tabular}

TCSA $=$ trunk cross-sectional area; LCSA $=$ limb cross-sectional area.

wood, with the primary bearing surface comprising spurs on wood that is at least 2 years old.

In the past, the volume and branching complexity of apple tree canopies made it difficult to create a simple, predictable, and repeatable whole tree metric of pruning severity. Much of the literature addressing pruning severity of apple is for heading cuts made on young trees in training systems with permanent scaffolds. The effects of varying renewal pruning severity in spindle systems seems little studied, yet this style of pruning and orchard system are becoming predominant. The adoption of smaller, simplified tree canopies should allow an accurate and repeatable method for establishing pruning severity levels to be developed. To our knowledge, no whole-tree studies that quantify pruning severity have been attempted.

Trunk cross-sectional area (TCSA) has a positive linear relationship with total aboveground weight, can be used to estimate the bearing surface of a tree (Westwood and Roberts, 1970) and is frequently used by pomologists to standardize fruit number per tree based on tree size (Lombard et al., 1988). Similarly, calculating crop density of limbs (LCSA) is an effective subsampling technique for estimating crop density (Forshey and Elfving, 1979). As part of the centrifugal training system (Lauri et al., 2004) a handthinning gauge was developed to estimate the target crop load of a limb, based on limb crosssectional area (Equilifruit; INRA, Montpelier, France). Kon and Schupp (2013) demonstrated that use of the hand-thinning gauge was effective in tall spindle trees, but suggested that yield and final crop density would be a function of total limb cross-sectional area. Thus, identifying the optimal ratio of LCSA to TCSA seemed to be a logical approach to establishing pruning severity thresholds.

Goals for cropload adjustment are partially met through removal of potential fruiting sites, the most drastic of which is whole-limb removal. We hypothesized that combining the per-branch crop load goals indicated by Lauri et al. (2004), with the whole-tree cropload goals given in Kon and Schupp (2013), appropriate levels of pruning severity could be specified to achieve specific cropload potentials for given tree sizes. Removal of fruiting structures could be carried out by whole-limb pruning alone to achieve a favorable balance between limb area and tree size.

Here we propose and implement a method for quantifying renewal pruning severity in the tall spindle system that involves measurement of all limb structures as they emanate from the spindle and sequential removal of 


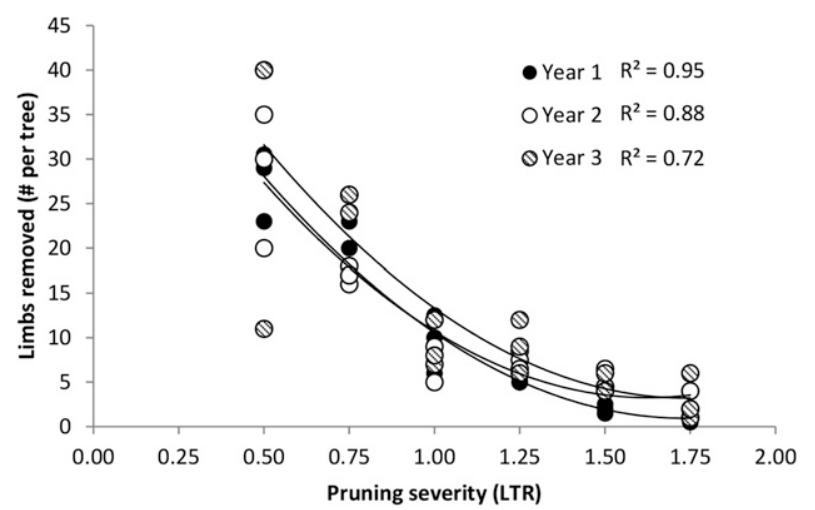

Fig. 1. The number of limbs removed per tree to obtain the six prescribed levels of pruning severity on 'Buckeye Gala' in the 3 years of the study. Limb to trunk ratio (LTR) is defined as the ratio between the summation of the limb cross sectional area for all limbs on the tree divided by the cross sectional area of the trunk at $30 \mathrm{~cm}$ above the graft union. Its values are the inverse of pruning severity with higher LTR values indicating less severe pruning.

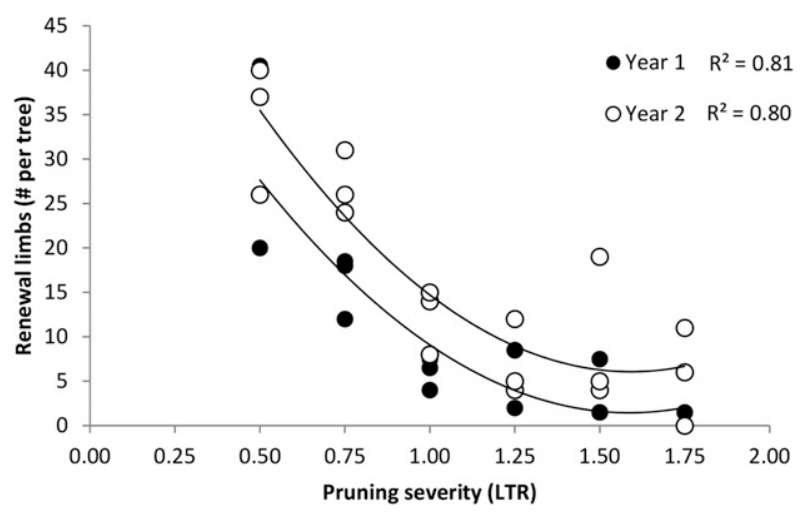

Fig. 2. Renewal limbs per tree, counted at the end of the seasonal growth period as influenced by pruning severity [limb to trunk ratio (LTR)]. Renewal limbs are defined here as number of new limbs growing from the central leader in the growing season after pruning treatment. LTR is defined as the ratio between the summation of the limb cross sectional area for all limbs on the tree divided by the cross sectional area of the trunk at $30 \mathrm{~cm}$ above the graft union. Its values are the inverse of pruning severity with higher LTR values indicating less severe pruning.

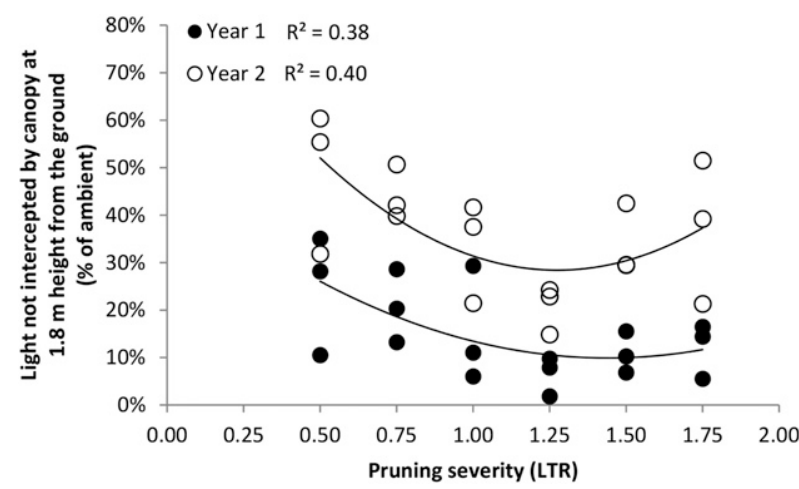

Fig. 3. Average photosynthetically active radiation levels relative to ambient light measured $1.8 \mathrm{~m}$ from the ground for six levels of pruning severity in the first 2 years of the study. Limb to trunk ratio (LTR) is defined as the ratio between the summation of the limb cross sectional area for all limbs on the tree divided by the cross sectional area of the trunk at $30 \mathrm{~cm}$ above the graft union. Its values are the inverse of pruning severity with higher LTR values indicating less severe pruning.

largest branches until a required pruning severity index value is reached. The goals of this study are to quantify renewal pruning severity, implement treatments of varying levels of severity, assess the vegetative and fruiting responses of trees to these severity levels, and provide consistent quantifiable guidelines for pruning severity. Such guidelines could provide engineers and horticulturists with measurable and sound rules for designing automated pruning devices and systems.

\section{Materials and Methods}

This study was conducted on 10-year-old 'Buckeye Gala'/‘M.9' apple trees growing at The Pennsylvania State University Fruit Research and Extension Center in Biglerville, PA. Trees were planted at $1.2 \mathrm{~m} \times 4.6 \mathrm{~m}$ spacing (1,784 trees per hectare), trained to a tall spindle, and were $\approx 3.5 \mathrm{~m}$ tall, with no side branches below $0.5 \mathrm{~m}$ height. Trees received crop protectant sprays, fertilizers, irrigation, and chemical thinners in accordance with the local recommendations.

Eighteen 3-tree plots were selected, trunk circumferences were measured at $30 \mathrm{~cm}$ above the graft union, and TCSA $\left(\mathrm{cm}^{2}\right)$ was calculated. The diameter of each primary limb was measured with digital calipers at $\approx 2.5 \mathrm{~cm}$ from its union to the central leader, and its cross-sectional area was calculated (LCSA, $\mathrm{cm}^{2}$ ). The sum of the LCSA for all primary limbs on each tree was divided by the TCSA of each tree to give the LTR as

$$
\mathrm{LTR}=\frac{\sum_{i=0}^{n} \mathrm{LCSA}_{i}}{\mathrm{TCSA}}
$$

where $n$ is the number of primary branches on the tree, excluding the central leader, and $L C S A_{i}$ is the cross-sectional area of the $i$ th primary limb, and TCSA is the cross-sectional area of the central leader (trunk) at $30 \mathrm{~cm}$ above the graft union. Pruning treatments were then applied to obtain prescribed LTRs representing six levels of renewal pruning severity. To obtain the ratios specified for each LTR treatment level limbs were removed in sequence starting with the limb with the largest caliper, then the limb with the next largest caliper, etc. After each limb was removed, the LTR was recalculated. The prescribed pruning levels in increasing severity were $\mathrm{LTR}=1.75,1.50,1.25,1.00$, 0.75 , and 0.50 . The pruning procedure ended for each tree when the prescribed LTR was obtained. To determine cumulative effects, pruning treatments were applied to the same plots during the winter dormant periods after the 10th, 11th, and 12th leaf growing seasons.

Using data collected before treatment, TCSA, limb number per tree, LCSA, and the number of limbs retained after pruning were characterized. In addition, the number and LCSA of removed limbs were tracked during treatment application. Total fresh weight of pruned limbs was determined using a field scale (ES50L; Ohaus, Parsippany, NJ).

One tree per plot was designated for morphometric limb characterization, a quantitative analysis of limb morphology. After seasonal growth was complete, five representative limbs with LCSA between 3.8 and 15.9 $\mathrm{cm}^{2}$ were excised from the tops $(>2.4 \mathrm{~m}$ tree height) and five from the bottoms $(<2.4 \mathrm{~m}$ tree height) of the sacrificial trees in year 1 of the study. The age of each excised primary limb was determined by counting terminal 
Table 3. The influence of pruning severity on limb characterization data for limbs excised in year 1 of the study.

\begin{tabular}{|c|c|c|c|c|c|c|c|c|}
\hline Pruning severity level (LTR) & $\begin{array}{l}\text { Limb } \\
\text { age (yr) }\end{array}$ & $\begin{array}{l}\text { Secondary } \\
\text { limbs (no.) }\end{array}$ & $\begin{array}{c}\text { Shoots per } \\
\text { unit limb } \\
\text { area }\left(\text { no. } \mathrm{cm}^{-2}\right)\end{array}$ & $\begin{array}{l}\text { Shoot length } \\
\text { per unit limb } \\
\text { area }\left(\mathrm{cm} \cdot \mathrm{cm}^{-2}\right)\end{array}$ & $\begin{array}{l}\text { Shoot leaves } \\
\text { per unit limb } \\
\text { area }\left(\text { no. } \mathrm{cm}^{-2}\right)\end{array}$ & $\begin{array}{c}\text { Spurs per } \\
\text { unit limb } \\
\text { area }\left(\text { no. } \mathrm{cm}^{-2}\right)\end{array}$ & $\begin{array}{l}\text { Spur leaf area } \\
\text { per unit limb } \\
\text { area }\left(\mathrm{cm}^{2} \cdot \mathrm{cm}^{-2}\right)\end{array}$ & $\begin{array}{c}\text { Spur leaf } \\
\text { area: shoot leaf } \\
\text { area }\left(\mathrm{cm}^{2}: \mathrm{cm}^{2}\right)\end{array}$ \\
\hline 1.75 & 5.7 & 4 & 3.2 & 15.5 & 30.9 & 33.5 & 2,364 & 19.8 \\
\hline 1.50 & 4.8 & 4 & 5.1 & 12.7 & 34.3 & 46.1 & 2,475 & 25.8 \\
\hline 1.00 & 4.2 & 3 & 6.3 & 15.0 & 70.9 & 25.2 & 1,988 & 6.0 \\
\hline 0.75 & 4.9 & 2 & 5.4 & 19.2 & 64.7 & 22.2 & 1,663 & 9.3 \\
\hline 0.50 & 4.3 & 1 & 9 & 20.8 & 112.2 & 16.1 & 1,202 & 8.7 \\
\hline Position & 0.19 & 0.623 & 0.532 & 0.214 & 0.792 & 0.383 & 0.405 & 0.948 \\
\hline Treatment (linear) & 0.001 & 0.043 & 0.004 & 0.072 & 0.001 & 0.003 & 0.005 & 0.023 \\
\hline Position $\times$ Treatment (linear) & 0.681 & 0.375 & 0.687 & 0.424 & 0.564 & 0.365 & 0.880 & 0.944 \\
\hline \multicolumn{9}{|c|}{ Linear regression pooled over positions ${ }^{y}$} \\
\hline$R^{2}$ & 0.05 & 0.37 & 0.25 & 0.09 & 0.51 & 0.33 & 0.28 & 0.15 \\
\hline$P$ value for slope & 0.196 & 0.001 & 0.002 & 0.075 & 0.001 & 0.001 & 0.007 & 0.019 \\
\hline
\end{tabular}

${ }^{\mathrm{z}}$ Data were analyzed with Proc Mixed to test main effects and the interaction of treatment and position. The quadratic term for treatment was not significant for any response variables.

${ }^{\mathrm{y}}$ Linear regression was performed with Proc Reg for data pooled over position because the main effect of position and the position $\times$ treatment interactions were not significant at the $5 \%$ level. The quadratic term was not significant for any response variables.

$\mathrm{LTR}=\operatorname{limb}$ to trunk ratio.

Table 4. Flowering, fruiting, yield, and crop value data as affected by pruning severity treatments over 2 years. Significant regression model terms are listed below the means for each response variable. ${ }^{\mathrm{z}}$

\begin{tabular}{|c|c|c|c|c|c|c|c|c|c|c|}
\hline $\begin{array}{l}\text { Pruning severity } \\
\text { level (LTR) }\end{array}$ & $\mathrm{Yr}$ & $\begin{array}{l}\text { Flower cluster } \\
\text { density }\left(\text { no. } \mathrm{cm}^{-2}\right)\end{array}$ & $\begin{array}{c}\text { Final } \\
\text { fruit set (\%) }\end{array}$ & $\begin{array}{c}\text { Yield } \\
\text { efficiency } \\
\left(\mathrm{kg} \cdot \mathrm{cm}^{-2}\right)\end{array}$ & $\begin{array}{c}\text { Yield } \\
\text { per tree }(\mathrm{kg})\end{array}$ & $\begin{array}{l}\text { Mean fruit } \\
\text { size }(\mathrm{g})\end{array}$ & $\begin{array}{l}\text { Yield }>70 \\
\mathrm{~mm} \cdot \mathrm{kg}^{-1}\end{array}$ & $\begin{array}{l}\text { Crop value, } \\
<70 \mathrm{~mm} \text { fruits } \\
\text { (\$ per tree) }\end{array}$ & $\begin{array}{l}\text { Crop value, } \\
>70 \text { mm fruits } \\
(\$ \text { per tree })\end{array}$ & $\begin{array}{l}\text { Crop value, } \\
\text { all sizes } \\
(\$ \text { per tree) }\end{array}$ \\
\hline 1.75 & 1 & 22.9 & 38.7 & 1.37 & 39.7 & 124 & 5.5 & 12.31 & 4.14 & 16.80 \\
\hline 1.50 & & 17.8 & 43.0 & 1.37 & 50.6 & 121 & 5.5 & 16.51 & 4.33 & 20.84 \\
\hline 1.00 & & 19.3 & 52.3 & 1.27 & 48.6 & 140 & 16.3 & 10.66 & 10.47 & 21.13 \\
\hline 0.75 & & 15.2 & 90.0 & 0.95 & 26.5 & 149 & 8.9 & 6.32 & 5.32 & 11.64 \\
\hline 0.50 & & 14.2 & 63.7 & 0.67 & 22.2 & 181 & 16.2 & 1.73 & 8.88 & 10.61 \\
\hline 1.50 & & 19.5 & 33.7 & 0.90 & 36.7 & 122 & 8.0 & 11.46 & 3.65 & 15.12 \\
\hline 1.25 & & 20.3 & 21.7 & 0.65 & 30.1 & 125 & 7.4 & 9.19 & 3.37 & 12.55 \\
\hline 1.00 & & 18.8 & 29.7 & 0.69 & 20.7 & 145 & 15.8 & 5.73 & 7.35 & 13.07 \\
\hline 0.75 & & 18.2 & 76.0 & 0.50 & 15.0 & 151 & 8.5 & 3.03 & 4.02 & 7.05 \\
\hline 0.50 & & 23.8 & 49.7 & 0.33 & 13.0 & 171 & 10.0 & 1.24 & 4.81 & 6.05 \\
\hline \multicolumn{11}{|l|}{$P$ value } \\
\hline
\end{tabular}

z - indicates that the term was not significant at the $5 \%$ level and was deleted during the model selection process.

LTR $=$ limb to trunk ratio.

bud-scale scars. The number of secondary limbs emanating from each excised limb was counted. The numbers of shoots, spurs, leaves on shoots, and leaves on spurs were counted and normalized per unit square centimeter LCSA. The total length of shoots was measured for each excised limb and expressed as a unit of length per unit LCSA. The total leaf area for each limb, after segregating leaves emanating from spurs and shoots, was measured using a leaf area meter (LI-3100; LI-COR Biosciences, Lincoln, NE).

Two of the three trees in each plot were designated for harvest and received no further modification after each year's pruning. On these trees, two to three uniform limbs were selected and flagged. Basal limb crosssectional area was determined and blossom clusters were counted and recorded. After June drop, fruit number was counted on selected limbs and crop density (number of fruit per square centimeter LCSA) was calculated. In the first 2 years of the study, yield, crop load, and fruit size data were measured for each of the eighteen 2-tree plots by harvesting whole trees and weighing all fruit on an electronic single-lane fruit sizer equipped with a digital load-cell (DurandWayland, Inc., LaGrange, GA). Crop value was estimated on the basis of yield, fruit size, and quality characteristics using prices obtained from a major local fruit packer. Yield efficiency was calculated by dividing total yield by trunk cross-sectional area at harvest. The cropping portion of the study ended after year 2 .
During the first and second growing seasons of the study, photosynthetically active radiation $(P A R)$ was measured on days of uniform light conditions within the canopy of all unmodified harvest data trees at $1.8 \mathrm{~m}$ height aboveground with a $1 \mathrm{~m}$ light meter (LI-COR LI-250A) on the east and west sides of the canopy at 1000 and 1400 HR. We attempted to obtain one measurement on a cloud-free day and one measurement on a uniformly cloudy day. One set of measurements was taken in June and one in August. Instantaneous ambient measurements of unshaded sky were recorded and the percentage of ambient $P A R$ not captured by the canopy was calculated. Before pruning and at the end of the first and second growing seasons, all limbs on each tree were counted and the 


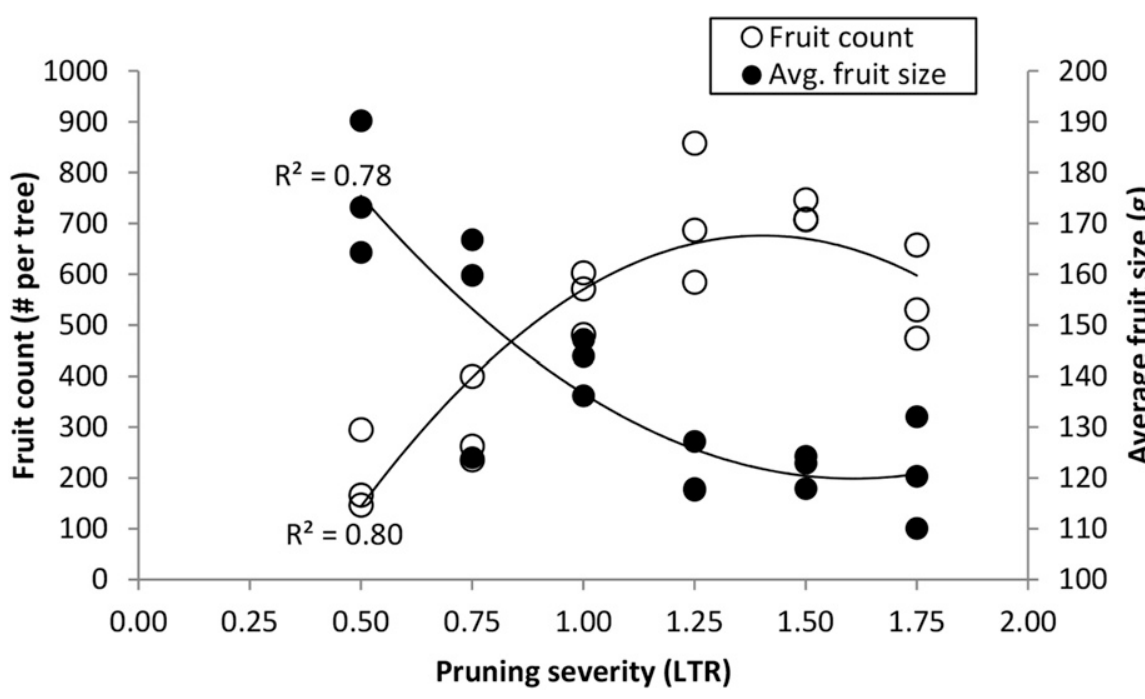

Fig. 4. The influence of pruning severity [limb to trunk ratio (LTR)] on number of fruit harvested per tree and average fruit weight for the 2 years. LTR is defined as the ratio between the summation of the limb cross sectional area for all limbs on the tree divided by the cross sectional area of the trunk at $30 \mathrm{~cm}$ above the graft union. Its values are the inverse of pruning severity with higher LTR values indicating less severe pruning.

Table 5. Regression models for variables shown in Table 4 and Fig. 4 obtained from the solution matrix with Proc Mixed.

\begin{tabular}{|c|c|c|}
\hline Variable & $\mathrm{Yr}$ & Regression model \\
\hline \multirow[t]{2}{*}{ Fruit count (no. per tree) } & 1 & $-420.85+1,251.5 \operatorname{trt}-465.76 \operatorname{trt}^{2}$ \\
\hline & 2 & $-187.75+579.5 \operatorname{trt}-186.7 \operatorname{trt}^{2}$ \\
\hline \multirow[t]{2}{*}{ Yield efficiency $\left(\mathrm{kg} \cdot \mathrm{cm}^{-2}\right)$} & 1 & $0.06+1.65 \operatorname{trt}-0.52 \operatorname{trt}^{2}$ \\
\hline & 2 & $-0.46+1.65 \operatorname{trt}-0.52 \operatorname{trt}^{2}$ \\
\hline \multirow[t]{2}{*}{ Yield per tree $(\mathrm{kg})$} & 1 & $-20.69+103.7 \mathrm{trt}-38.45 \operatorname{trt}^{2}$ \\
\hline & 2 & $-35.56+103.7 \mathrm{trt}-38.45 \operatorname{trt}^{2}$ \\
\hline Average fruit size $(\mathrm{g})$ & Both & $224.9-121.26 \mathrm{trt}+34.67 \mathrm{trt}^{2}$ \\
\hline Yield $>70 \mathrm{~mm}$ diam. per tree $(\mathrm{kg})$ & Both & $16.2-5.96 \mathrm{trt}$ \\
\hline \multirow[t]{2}{*}{ Crop value, $<70 \mathrm{~mm}$ diam. fruits, per tree $(\$)$} & 1 & $-20.92+52.17 \operatorname{trt}-18.60 \operatorname{trt}^{2}$ \\
\hline & 2 & $-9.78+23.61 \operatorname{trt}-7.36 \operatorname{trt}^{2}$ \\
\hline \multirow[t]{2}{*}{ Crop value, $>70 \mathrm{~mm}$ diam. fruits, per tree $(\$)$} & 1 & $8.91-2.33 \mathrm{trt}$ \\
\hline & 2 & $6.95-2.33 \operatorname{trt}$ \\
\hline \multirow[t]{2}{*}{ Crop value, all sizes, per tree $(\$)$} & 1 & $-6.10+40.02 \operatorname{trt}-14.99 \operatorname{trt}^{2}$ \\
\hline & 2 & $-12.48+40.02 \operatorname{trt}-14.99 \operatorname{trt}^{2}$ \\
\hline
\end{tabular}

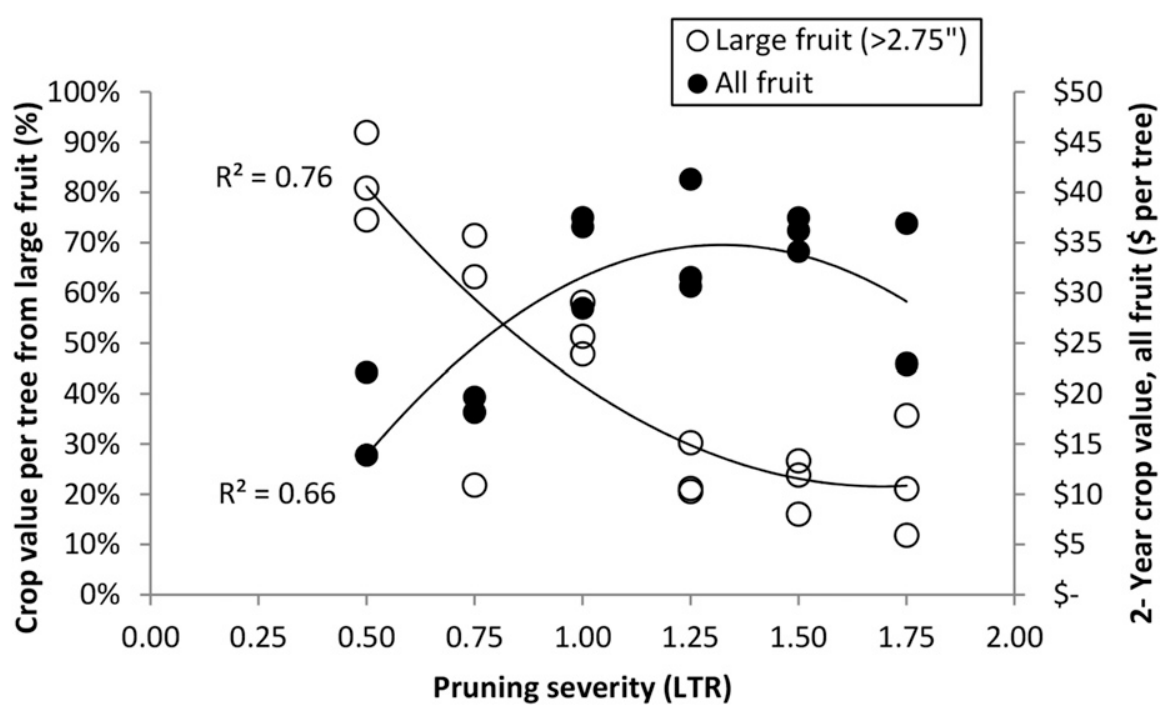

Fig. 5. The influence of pruning severity [limb to trunk ratio (LTR)] on crop value (\$ per tree) for the 2 years of the study, and the percentage of crop value from large $(>70 \mathrm{~mm}$ in diameter) fruit. LTR is defined as the ratio between the summation of the limb cross-sectional area for all limbs on the tree divided by the cross-sectional area of the trunk at $30 \mathrm{~cm}$ above the graft union. Its values are the inverse of pruning severity with higher LTR values indicating less severe pruning. diameter of each was measured using digital calipers. The LTR was calculated for each tree after harvest, and the increase in LTR from the time at which the tree received pruning treatments was calculated. All renewal shoots on each tree were identified and counted. Renewal shoots were identified as shoots emanating from stubs from previously cut limbs from the spindle.

During the first 2 years of the study a 20 fruit sample from each data tree, representing a fruit size range of 110-200 g, was used to evaluate fruit quality. Fruit firmness was measured with a fruit texture analyzer (2005FTA; Güss, Strand, South Africa). Juice samples were collected and soluble solids concentration was measured with a digital refractometer (PR-32 $\alpha$; Atago U. S. A. Inc., Bellevue, WA). Juice samples were also tested for titratable acidity and $\mathrm{pH}$ with a mini-titrator and $\mathrm{pH}$ meter (HI 84432; Hanna Instruments, Woonsocket, RI). Fruit surface color was measured with a spectrophotometer (CM-2600d; Konica Minolta Sensing Inc., Osaka, Japan). Colorimetry was performed in CIE $L^{*} C_{\mathrm{ab}} * h_{\mathrm{ab}}$ color space of International Commission on apple surfaces, where $L^{*}$ represents the lightness of the color, $C_{\mathrm{ab}} *$ represents chroma, or saturation intensity, and $h_{\mathrm{ab}}$ represents hue, or the angular component of the polar representation of CIELAB color space (Commission Internationale de 1-Eclairage, 1978). One reading was taken on the most highly blushed side of the fruit and another reading on the opposite background color side. The reference illuminant was D65 and the observer angle was set to $2^{\circ}$.

Statistical analysis. The assumption of sphericity was rejected for only one response variable, indicating that a repeated measures analysis was not necessary for data collected over time (Littell et al., 2002). Because variances were heterogeneous for most response variables, unequal variance models were fit with Proc Mixed (Littell et al., 2006), where block was specified as a random effect, and year and position were specified as fixed effects class variables, and pruning treatment was included as a regressor variable. Appropriate models were identified with the approach explained by Milliken and Johnson (2002) and Myers (1990), and intercepts and slopes were requested with the Noint and Solution options in the model statement. When treatment was the only significant variable in the model, the data were analyzed by simple linear regression with Proc Reg to obtain the coefficient of determination with the realization that variation because of block would be pooled into the error term.

\section{Results and Discussion}

The number of limbs removed, the total limb cross-sectional area removed, the weight of limbs removed, and the number of renewal limbs originating in the growing season after pruning were increased with increasing pruning severity, whereas the average limb cross-sectional area decreased 


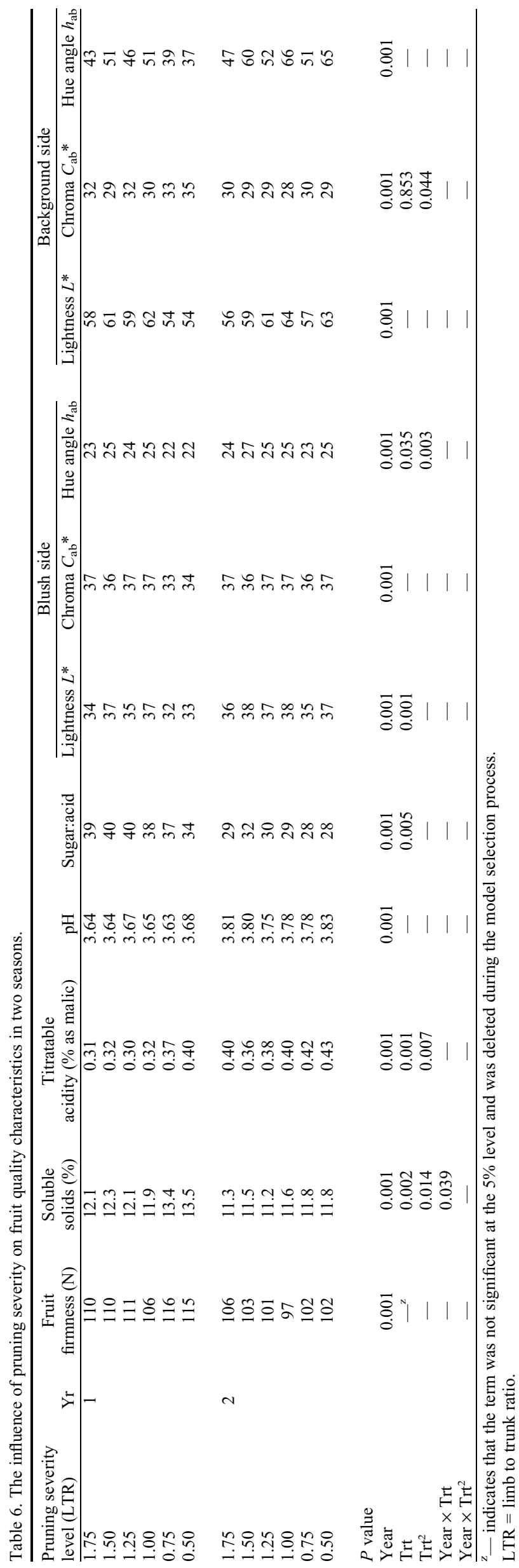

(Table 1; Fig. 1). Regression models describing the effect of pruning severity of each response variable are presented in Table 2 . The number of renewal limbs per tree increased linearly with pruning severity (Fig. 2). The total LCSA before pruning, however, was only weakly related to the pruning severity, whereas the increase in the LTR during the growing season was strongly related to pruning severity. This indicates that more severely pruned trees had more vigorous growth, producing greater amounts of LCSA during the growing season. The number of limbs removed increased with pruning severity in a quadratic manner as limbs were removed in order from largest to next-largest (Fig. 1). Severely pruned trees had more small limbs removed than less severely pruned trees, each limb removed contributing successively less than the previous removed limb to the decrease in LTR. Removal of numerous small shoots stimulates more new shoot growth than removal of a few larger branches of comparable fresh weight (Mika, 1986).

Annual dormant pruning is an important practice to improve light distribution within the canopy (Ferree and Schupp, 2003; Forshey et al., 1992). Average values of $P A R$ measured in the canopy followed a quadratic pattern, especially in year 2, with greater light interception values for the less severely pruned trees (Fig. 3). Maximal light interception was observed at LTR 1.25 for two consecutive years.

The age of primary limbs excised in the 2 years of observations decreased with increasing pruning severity, indicating that greater pruning severity led to an overall younger limb age (Table 3). The number of secondary limbs tended to decrease with increasing levels of renewal pruning severity. Trees that were more severely pruned had a higher propensity for partitioning growth into shoots rather than spurs, with higher values for shoot length, shoot leaves, and shoot leaf area than their less severely pruned counterparts. Less severely pruned trees had a higher propensity for partitioning growth into spurs rather than shoots, producing a higher number of spurs per unit limb size, with more spur leaves, higher spur leaf area, and greater values for the ratio of spur leaf area to shoot leaf area (Table 3). Lakso (1984) also found that "moderately" pruned 'Empire'/'M.7' apple trees had lower spur leaf area and greater shoot leaf area than nonpruned trees.

Fruit set per 100 blossom clusters increased with increasing pruning severity, whereas fruit number per tree, yield efficiency, and yield decreased with increasing number of limbs removed (Tables 1-4). Cumulative fruit count per tree for the 2 years of cropping data in the study was strongly related to pruning severity (Table 4). Fruit set as a percentage of initial blossom clusters tended to increase in a quadratic pattern with increasing pruning severity. Fruit count decreased and average fruit size increased with increasing pruning severity in 
Table 7. Regression models for variables shown in Table 6 obtained from the solution matrix with Proc Mixed.

\begin{tabular}{lll}
\hline Variable & Yr & Regression model \\
\hline Firmness $^{2}(\mathrm{~N})$ & 2014 & 11.35 \\
Soluble solids (\%) & 2015 & 10.38 \\
& 2014 & $15.75-5.13 \mathrm{trt}+1.78 \mathrm{trt}^{2}$ \\
Titratable acidity (\% as malic) & 2015 & $12.47-1.32 \mathrm{trt}+0.39 \mathrm{tr}^{2}$ \\
$\mathrm{pH}$ & 2014 & $0.49-0.27 \mathrm{trt}+0.094 \mathrm{trt}^{2}$ \\
& 2015 & $0.56-0.27 \mathrm{trt}+0.094 \mathrm{trt}^{2}$ \\
Sugar:acid & 2014 & 3.65 \\
Blush lightness, $L^{*}$ & 2015 & 3.79 \\
& 2014 & $34.31+3.23 \mathrm{trt}$ \\
Blush chroma, $C_{\mathrm{ab}}{ }^{*}$ & 2015 & $25.56+3.23 \mathrm{trt}$ \\
& 2014 & $34.50+3.06 \mathrm{trt}$ \\
Blush hue angle, $h_{\mathrm{ab}}$ & 2015 & $25.76+3.06 \mathrm{trt}$ \\
& 2014 & 34.77 \\
Background lightness, $L^{*}$ & 2015 & 36.88 \\
& 2014 & $32.00+3.17 \mathrm{trt}$ \\
Background chroma, $C_{\mathrm{ab}}{ }^{*}$ & 2015 & $36.61-0.022 \mathrm{trt}$ \\
Background hue angle, $h_{\mathrm{ab}}$ & 2014 & 23.47 \\
& 2015 & 25.01 \\
\hline
\end{tabular}

${ }^{\mathrm{z}}$ Means for year are presented where only year was significant.

a quadratic pattern (Fig. 4; Table 5). Pruning more severely than LTR 1.0 resulted in a precipitous decline in yield accompanied by a sharp rise in fruit size. The amount of yield of fruit larger than $70 \mathrm{~mm}$ in diameter increased with increased pruning severity, but overall crop value per tree was highest for the moderately pruned (LTR 1.0-LTR 1.25) trees (Fig. 5). Within the intermediate severity range, LTR 1.0 produced the largest income from larger sized fruits, whereas severity in the LTR 1.25-1.5 range resulted in the highest income based on smaller fruit sizes, suggesting that, within this range, pruning severity can be adjusted to meet anticipated market demand for larger or smaller fruit.

Internal fruit quality improved with increasing pruning severity, with greater soluble solids concentration and acidity in juice samples for more severely pruned trees than for less severely pruned trees (Tables 6 and 7). Fruit blush showed a quadratic response to hue angle on the blush sides of fruit and chroma on the background sides of the fruit with greater degrees of redness on the blush sides of fruit at both extremes of pruning severity. The minimal impact of pruning severity treatments on fruit quality in this study can be attributed to the sequential removal of the largest limbs. The least severe pruning still removed the largest limbs, thereby improving light distribution, with minimal regrowth, which was largely restricted to the inner canopy, close to the spindle.

Aside from managing tree height, current recommendations for pruning mature tall spindle apple include the removal to two to three of the largest limbs per tree (Robinson et al., 2006). In all 3 years of this study, this heuristic would have resulted in the least severe pruning treatments (Year $1 \mathrm{LTR}=$ 1.50; Year 2 and 3 LTR $=1.75$ ). In this experiment, moderate levels of pruning severity resulted in the greatest crop value, such that pruning severity between LTR 1.5 and 1.25 is desirable on mature tall spindle 'Gala'. Achieving this level of pruning severity may require more extensive pruning than currently recommended in the tall spindle training system.

We initiated this research to develop appropriate pruning severity guidelines for optimal fruit production. We evaluated a systematic approach to dormant pruning severity, based on successively removing the largest primary limbs. This system provides orchard managers or engineers with a predictable, repeatable method of increasing severity based on measurements that are easily obtained and which have a simplified locus at the spindle. Calculation of LTR requires only identification and measurement of the trunk diameter at $30 \mathrm{~cm}$ height and the diameter of each primary limb near its point of origin. Such guidelines would serve to provide engineers with measurable parameters for developing appropriate sensors and targets for developing automated pruning. The appropriate LTR will likely need to be established for different orchard systems, and optimal values may differ for given tree planting densities, cultivars, marketplace preferences, etc. For a given set of orchard conditions response data from trees at varying pruning severity levels can be analyzed and tabulated to show linear relationships between tree response and severity level (Tables 2 and 5). These linear relationships, once established, can provide optimum pruning severity criteria for a given set of desired orchard outcomes.

Horticulturists have often cited the "art and science of pruning." With the advent of uniform narrow canopy training systems on dwarfed trees with a simple branching structure enforced by renewal pruning, the "art- istry" can be phased out in favor of pruning to measurable and repeatable levels of severity. The proposed severity rule is compatible with the tenants of tall spindle pruning, which calls for renewal of large limbs (Robinson, et al., 2006). The LTR provides a measurable way to define and create different levels of pruning severity and achieve consistent outcomes. This allows a greater degree of accuracy and precision to dormant pruning of tall spindle apple trees.

Use of the LTR to establish the level of pruning severity allows the orchard manager to set crop load potential through regulation of the canopy bearing surface. Removal of the largest limbs promotes good distribution of sunlight by removing the greatest amount of shading canopy with the least amount of re-growth. With 'Gala', the increase in fruit size shifted in relationship to the corresponding reduction in cropping resulting from incremental increases in LTR. Our results suggest that LTR between 1.5 and 1.0 for mature 'Buckeye Gala'/'M.9' would produce the best economic outcome, based on yield, fruit size, and fruit quality. Within that range, the LTR could be adjusted for anticipated market requirements. Optimal LTRs for other cultivar/rootstock combinations may differ.

\section{Literature Cited}

Commission Internationale de 1-Eclairage. 1978. Recommendations on uniform color spaces, color difference equations, and metric color terms. Suppl. No. 2 to Pub. No. 15. Commission Internationale de 1-Eclairage, Paris, France.

Elfving, D.C. and C.G. Forshey. 1976. Growth and fruiting responses of vigorous apple branches to pruning and branch orientation treatments. J. Amer. Soc. Hort. Sci. 101:290-293.

Ferree, D.C. and J.R. Schupp. 2003. Pruning and training physiology, p. 319-344. In: D.C. Ferree and I.J. Warrington (eds.). Apples: Botany, production and uses. CABI Publishing, Wallingford, UK

Forshey, C.G. and D.C. Elfving. 1979. Branch samples for yield and fruit size comparisons in apple. HortScience 14:143-144.

Forshey, C.G., D.C. Elfving, and R.L. Stebbins. 1992. Training and pruning apple and pear trees. Amer. Soc. Hort. Sci., Alexandria, VA.

Fumey, D., P.É. Lauri, Y. Guédon, C. Godin, and E. Costes. 2011. How young trees cope with removal of whole or parts of shoots: An analysis of local and distant responses to pruning in 1 -year-old apple (Malus $\times$ domestica; rosaceae) trees. Amer. J. Bot. 98:1737-1751.

Gardner, V.R., F.C. Bradford, and H.D. Hooker. 1922. The fundamentals of fruit production. McGraw Hill, New York, NY.

Howe, G.H. 1923. Growth and yield of apple trees pruned in various ways, p. 4-10. Ch. 1. Little versus much pruning. N.Y. Agr. Expt. Sta. Bul. 500. NYAES, New York, NY.

Jonkers, H. 1982. Testing Koopmann's rules of apple tree pruning. Sci. Hort. 16:209-215.

Kon, T.M. and J.R. Schupp. 2013. Thinning tall spindle apple based on estimations made with a hand-thinning gauge. HortTechnology $23: 830-835$.

Lakso, A.N. 1984. Leaf area development patterns in young pruned and unpruned apple trees. J. Amer. Soc. Hort. Sci. 109:861-865.

Lauri, P.-E., M. Willaume, G. Larrive, and J.-M. Lespinasse. 2004. The concept of centrifugal 
training in apple aimed at optimizing the relationship between growth and fruiting. Acta Hort. 636:35-42.

Littell, R.C., G.A. Milliken, W.W. Stroup, R.D Wolfinger, and O. Schabenberger. 2006. SAS for mixed models. 2nd ed. SAS Inst., Cary, NC.

Littell, R.C., W.W. Stroup, and R.J. Freund. 2002. SAS for linear models. 4th ed. SAS Inst., Cary, NC.

Lombard, P.B., N.W. Callan, F.G. Dennis, N.E. Looney, G.C. Martin, A.R. Renquist, and E.A. Mielke. 1988. Towards a standardized nomenclature, procedures, values and units in determining fruit and nut tree yield performance. HortScience 23:813-817.

Marini, R.P. 2003. Peach yield, fruit weight, and crop value are affected by number off fruiting shoots per tree. HortScience 38:512-514.
Marini, R.P. and J.A. Barden. 1982a. Growth and flowering of vigorous apple trees as affected by summer or dormant pruning. J. Amer. Soc. Hort. Sci. 107:34-39.

Marini, R.P. and J.A. Barden. 1982b. Yield, fruit size, and quality of three apple cultivars as influenced by summer or dormant pruning. J Amer. Soc. Hort. Sci. 107:474-479.

Mika, A. 1986. Physiological responses of fruit trees to pruning. Hort. Rev. 8:337-378.

Milliken, G.A. and D.E. Johnson. 2002. Analysis of messy data. Vol. III: Analysis of covariance. Chapman and Hall/CRC, New York, NY.

Myers, R.H. 1990. Classical and modern regression with applications. 2nd ed. PWS-Kent, Boston, MA

Robinson, T.L. 2003. Apple orchard training systems, p. 345-408. In: D.C. Ferree and I.J.
Warrington (eds.). Apples: Botany, production and uses. CABI Publishing, Wallingford, UK.

Robinson, T.L., S.A. Hoying, and G.H. Reginato. 2006. The tall spindle apple production system. New York Fruit Qrtly. 14(2):21-28.

Seleznyova, A.N., G.A. Dayatilake, A.E. Watson, and D.S. Tustin. 2013. After initial invigoration by heading, young pear trees show reduction in axis vigor and increased propensity to flower. Funct. Plant Biol. 40:34-43.

Wertheim, S.J. 1968. The training of the slender spindle. Proefstation voor de Fruiteelt Wilheminadorp Publ. No. 7. p. 7

Westwood M.N. and A.N. Roberts. 1970. The relationship between trunk cross-sectional area and weight of apple trees. J. Amer. Soc. Hort. Sci. 95:28-30. 